IAC-09.A6.3.11

\title{
HONEYCOMB VS. FOAM: EVALUATING POTENTIAL UPGRADES TO ISS MODULE SHIELDING
}

\author{
S. Ryan \\ USRA Lunar and Planetary Institute (LPI), 3600 Bay Area Blvd, Houston, TX, 77058, USA \\ shannon.j.ryan@nasa.gov \\ E.L. Christiansen \\ NASA Johnson Space Center, 2101 NASA Pkwy, Houston, TX, 77058, USA \\ eric.l.christiansen@nasa.gov
}

\begin{abstract}
A series of 19 hypervelocity impact tests have been performed on ISS-representative structure walls to evaluate the effect on micrometeoroid and orbital debris (MMOD) protective capability caused by replacing honeycomb sandwich panel cores with metallic open-cell foam. In the experiments, secondary impacts on individual foam ligaments were found to raise the thermal state of projectile and bumper fragments, inducing break-up and melt at lower impact velocities than the baseline honeycomb configuration. A ballistic limit equation is derived for the foam-modified configuration, and in comparison with the honeycomb baseline a performance increase of 3-15\% at normal incidence was predicted. With increasing impact obliquity, the enhancement in protective capability provided by the modification is predicted to further increase. The reduction in penetration and failure risk posed by MMOD impacts is achieved by the foam-modified configuration without a significant decrease in mechanical or thermal performance, and with no additional weight. As such, it is considered a promising upgrade to MMOD shielding on ISS modules which incorporate honeycomb sandwich panels and are yet to fly.
\end{abstract}

\section{INTRODUCTION}

The performance of a dual-wall protective spacecraft structure against the impact of micrometeoroid and orbital debris (MMOD) particles is generally considered to be degraded by the presence of a honeycomb core. For impacts which penetrate the shield outer wall (bumper or front facesheet), projectile and bumper fragments disperse radially as they propagate through the shield interior, distributing the load over an area of the shield rear wall significantly larger than that of the original projectile diameter. The presence of honeycomb cell walls acts to restrict expansion, effectively channeling the fragments within a limited number of honeycomb cells for a more concentrated impact upon the rear facesheet. However, mission requirements often prevent the inclusion of a dedicated MMOD shielding structure, and as such, structural panels (i.e. honeycomb sandwich panels) also commonly serve as the protective system.

Metallic foams are a promising alternative to honeycomb structures as they offer comparable structural and thermal performance without the presence of MMOD shielding-detrimental channeling cells. In this paper, modifications to a double-layer honeycomb sandwich panel shielding configuration representative of those used onboard the International Space Station (ISS) are evaluated. The modifications entail the substitution of aluminum honeycomb for aluminum open-cell foams, while the total shield weight in maintained.

\section{BACKGROUND}

$\underline{\text { Honeycomb sandwich panels }}$

Given their common application in space vehicle primary structures, the performance of honeycomb under impact of MMOD particles at hypervelocity has been investigated in a multitude of studies. Jex et al. [1] and Sibeaud et al. [2] discussed that the presence of a honeycomb core enhanced the shielding performance of a dual-wall structure at hypervelocity. They concluded that secondary impacts between ejecta fragments and cell walls overcompensated for the detrimental effect of channeling. A more commonly held view is that the presence of a honeycomb core is unfavorable to the shielding performance. Taylor et al. [3] quantified the degradation in performance through inclusion of a scaling factor which acts to reduce the effective rear facesheet thickness by $50 \%$ in definition of the panel 
ballistic limit at hypervelocities (i.e. molten and/or vaporized ejecta). Ryan et al. [4] defined a degradation in shielding performance due to the presence of a honeycomb core equal to a $\sim 46 \%$ reduction in shielding capability at normal impact, reducing with increasing obliquity (e.g. for impact at $60^{\circ}$, the degradation in performance drops to $\sim 18 \%$ ). Sennett and Lathrop [5] also quantified the effect of the honeycomb core, stating that once the panel thickness increases above two times the honeycomb cell size, no increase in shielding capability is achieved with an increase in shield thickness when fragments were either molten or vaporized. For solid fragment ejecta, the effect was not nearly as severe. In Fig. 1, a comparison between the performance at 7 $\mathrm{km} / \mathrm{s}$ (normal impact) predicted for a dual-wall shield with and without a honeycomb core. For the Whipple shield configuration (i.e. no honeycomb core), the new non optimum (NNO) equation [6] is used. It should be noted that the NNO equation (and hence, the Taylor and Sennett \& Lathrop approaches) may provide non-conservative predictions for projectile diameter to shield spacing ratios $\left(S / d_{p}\right)<15$.

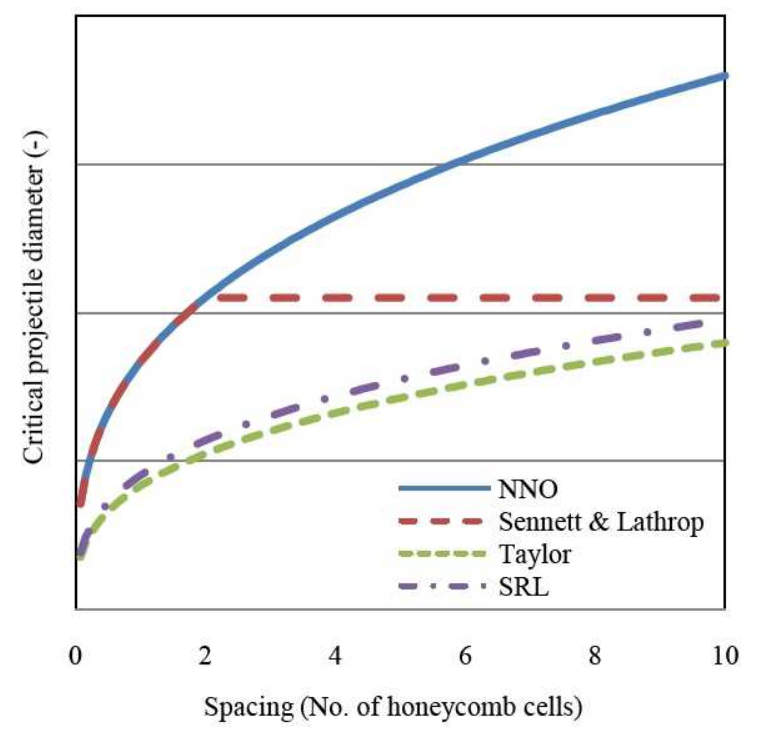

Fig. 1: Predicted performance for a dual-wall shield with and without a honeycomb core at hypervelocity.

\section{Open-cell foams}

Preliminary investigations of the hypervelocity impact performance of metal foam structures have demonstrated their potential, particularly in comparison with traditional structural panels. In [7] alternative configurations for the ISS Columbus module shielding were evaluated, one of which included an open-cell aluminum foam bumper. This configuration was found to provide increased protection over the reference Columbus stuffed
Whipple shield at high velocities $(>6 \mathrm{~km} / \mathrm{s})$ and normal incidence. For oblique angles, the performance was comparable to the reference configuration at high velocities. For low velocity testing, the performance of the foam-bumper configuration was clearly worse than the reference shield, due to the inability of the foam bumper to induce projectile fragmentation. Although the foam configuration provided a similar level of protection overall to the reference stuffed Whipple shield, the authors noted that the primary advantage of the modified configuration are related to the extended area of the pressure hull that can be protected (due to a concentration of mass in the outer later), and to other design aspects such as a reduction in nonballistic mass (stiffeners, local reinforcements, etc.).

The shielding performance of sandwich panel structures with open-cell aluminum foam cores was evaluated in [8] against that of aluminum honeycomb core sandwich panels (Al HC SP). In Fig. 2 a comparison between damages induced by nominally identical impacts are shown. It should be noted that the facesheets of the HC SP were significantly thicker than those of the foam panel in order to provide comparable areal densities. In the figure, the foam core is shown to restrict fragment radial expansion to an equal or greater degree than the HC. However, while fragments are expected to be channeled within the $\mathrm{HC}$ cells, the foam homogeneity should ensure that resistance to fragment cloud expansion is equal in all directions, therefore limiting the degree of channeling. For these impact conditions, the performance of the foam panel is shown to be clearly superior to that of the honeycomb panel.

\section{TARGET DEFINITION}

Double-laver honevcomb (DL-H)

The baseline target is constructed of two honeycomb sandwich panels, with two outer layers of stainless steel mesh and a monolithic aluminum rear wall, shown in Fig. 3. Details of the target components are provided in Table 1 . The total areal density of the DL-H configuration is $1.57 \mathrm{~g} / \mathrm{cm}^{2}$. 

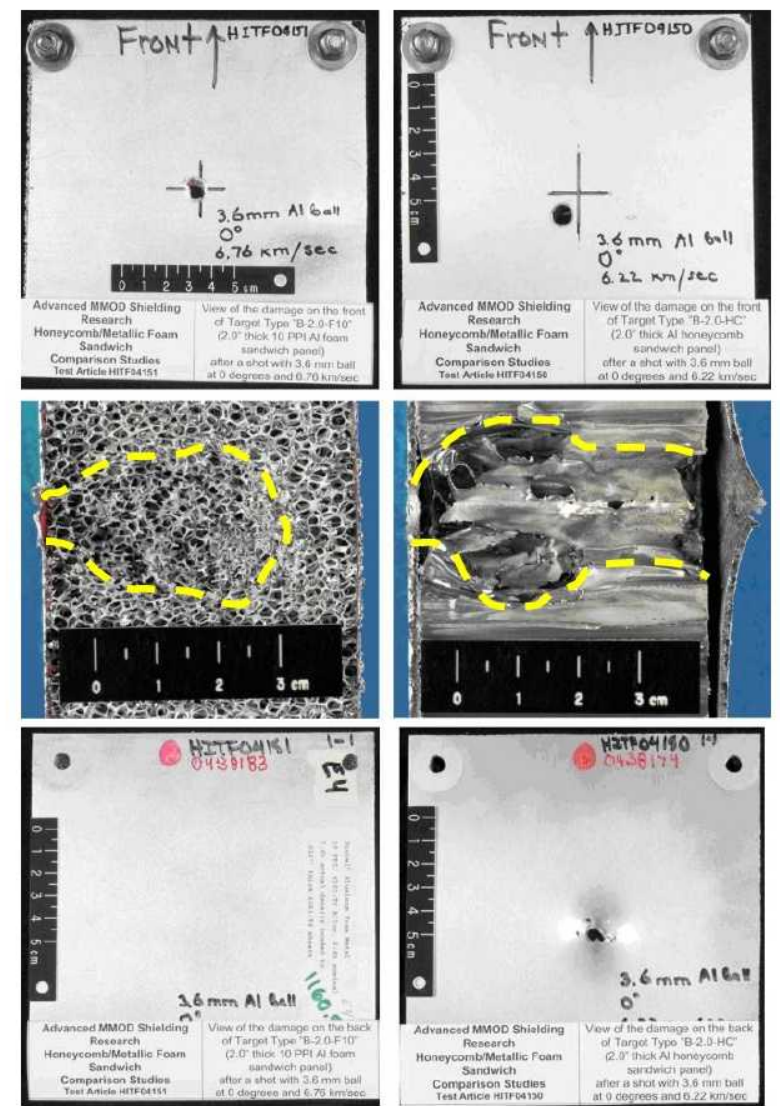

Fig. 2: Comparison of damages in open cell foam core (left) and honeycomb core (right) sandwich panel structures impacted by $3.6 \mathrm{~mm}$ Al-spheres at $6.49 \pm 0.27$ $\mathrm{km} / \mathrm{s}\left(0^{\circ}\right)$. From top to bottom: front facesheet, core (sectioned), rear facesheet.

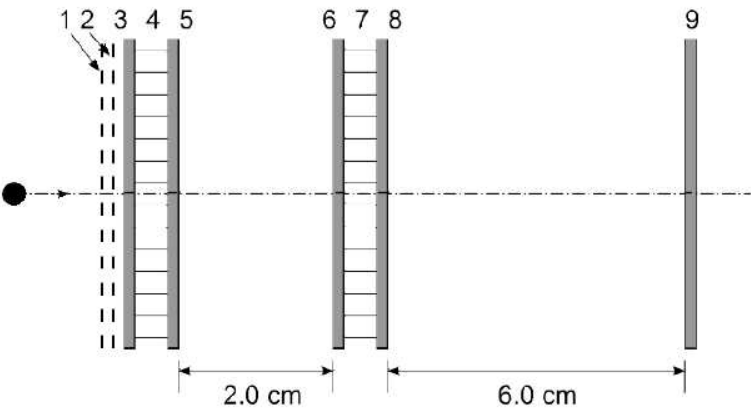

Fig. 3: Schematic of the double-layer honeycomb target.

\begin{tabular}{lllll}
\hline & Description & Designation & $\begin{array}{l}\text { Thickness } \\
(\mathrm{mm})\end{array}$ & $\begin{array}{l}\mathrm{AD} \\
\left(\mathrm{g} / \mathrm{cm}^{2}\right)\end{array}$ \\
\hline 1 & Mesh layer & $30 \times 30 \mathrm{SS} 304$ & 0.457 & 0.20 \\
2 & Mesh layer & $30 \times 30 \mathrm{SS} 304$ & 0.457 & 0.20 \\
3 & SP1 front FS & Al6061-T6 & 0.4064 & \\
4 & SP1 HC core & $1.8-5052-.002$ & 12.7 & 0.37 \\
5 & SP1 rear FS & Al6061-T6 & 0.4064 & \\
6 & SP2 front FS & Al6061-T6 & 0.4064 & \\
7 & SP2 HC core & $1.8-5052-.002$ & 12.7 & 0.37 \\
8 & SP2 rear FS & Al6061-T6 & 0.4064 & \\
9 & Real wall & Al2024-T3 & 1.016 & 0.43 \\
\hline
\end{tabular}

Table 1: Details of the DL-H target components.

\section{Double-layer foam (DL-F)}

In the DL-F configuration, the two honeycomb sandwich panels are replaced with $12.7 \mathrm{~mm}$ thick open-cell Al6101-T6 foam panels. As the areal weight of the foam core (6-8\% relative density) is greater than the honeycomb $(\sim 4.8 \%)$, facesheets are only installed on the first foam panel. The foam has a pore density of 10 per linear inch (PPI), details of which are given in Fig. 4. A schematic of the DL-F target is shown in Fig. 5, with details of target components provided in Table 2. The total areal density of the DL-F configuration is $1.68 \mathrm{~g} / \mathrm{cm}^{2}$.

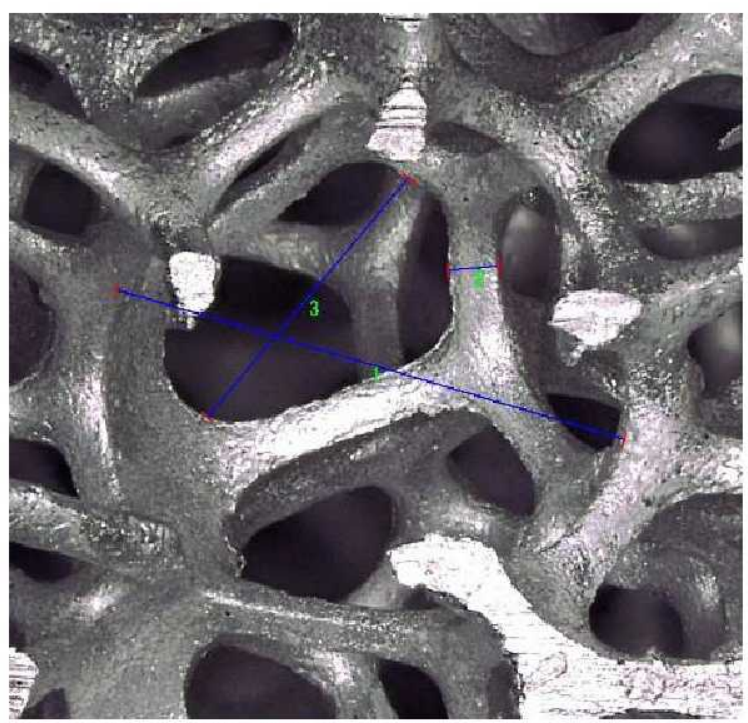

Fig. 4: Characterization of the 10 PPI foam structure. Cell size $(1)=3.95 \mathrm{~mm}$, ligament width $(2)=382 \mu \mathrm{m}$, pore size $(3)=2.33 \mathrm{~mm}$

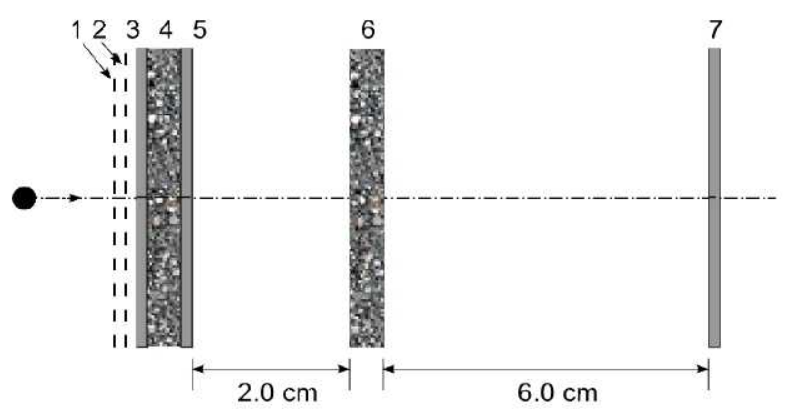

Fig. 5: Schematic of the double-layer foam target.

\begin{tabular}{lllll}
\hline & Description & Designation & $\begin{array}{l}\text { Thickness } \\
(\mathrm{mm})\end{array}$ & $\begin{array}{l}\mathrm{AD} \\
\left(\mathrm{g} / \mathrm{cm}^{2}\right)\end{array}$ \\
\hline 1 & Mesh layer $^{*}$ & $30 \times 30 \mathrm{SS} 304$ & 0.457 & 0.20 \\
2 & Mesh layer $^{*}$ & $30 \times 30 \mathrm{SS} 304$ & 0.457 & 0.20 \\
3 & SP1 front FS & Al6061-T6 & 0.4064 & \\
4 & SP1 foam core & 10 PPI Al6101-T6 & 12.7 & 0.56 \\
5 & SP1 rear FS & Al6061-T6 & 0.4064 & \\
6 & Foam panel & 10 PPI Al6101-T6 & 12.7 & 0.29 \\
7 & Real wall & A12024-T3 & 1.016 & 0.43 \\
\hline
\end{tabular}

Table 2: Details of the DL-F target components. 


\section{IMPACT TESTING AND RESULTS}

A series of 19 hypervelocity impact tests were performed on the double-layer targets using the two stage light gas guns at NASA JSC's White Sand's Test Facility (WSTF). A summary of the test conditions and results are presented in Table 3. For these tests, failure was defined as the ejection of material within the simulated pressure hull (i.e. perforation or detached spall of the target rear wall).

\begin{tabular}{lllllll}
\hline & Test & Target & $\begin{array}{l}\text { Angle } \\
(\mathrm{deg})\end{array}$ & $\begin{array}{l}\text { Diameter } \\
(\mathrm{cm})\end{array}$ & $\begin{array}{l}\text { Velocity } \\
(\mathrm{km} / \mathrm{s})\end{array}$ & Result \\
\hline 1 & 8592 & DL-F & 0 & 0.877 & 6.76 & Pass \\
2 & 8593 & DL-F & 45 & 0.837 & 6.87 & Pass \\
3 & 8594 & DL-F & 60 & 1.114 & 66.9 & Fail \\
4 & 8595 & DL-F & 0 & 0.717 & 3.29 & Fail \\
5 & 8599 & DL-F & 60 & 1.005 & 7.03 & Fail \\
6 & 8596 & DL-F & 0 & 0.637 & 3.67 & Fail \\
7 & 8597 & DL-F & 45 & 0.662 & 3.68 & Pass \\
8 & 8598 & DL-F & 45 & 0.837 & 3.62 & Pass \\
9 & 9024 & DL-F & 60 & 1.005 & 6.80 & Pass \\
10 & 9038 & DL-F & 60 & 1.115 & 6.69 & Pass \\
11 & 9064 & DL-F & 60 & 1.276 & 7.00 & Fail \\
12 & 7460 & DL-F & 0 & 0.833 & 6.74 & Pass \\
13 & 7461 & DL-F & 45 & 0.873 & 6.89 & Fail \\
14 & 7458 & DL-H & 45 & 0.754 & 6.94 & Pass \\
15 & 7459 & DL-H & 45 & 0.650 & 6.88 & Pass \\
16 & 7504 & DL-H & 0 & 0.730 & 6.86 & Pass \\
17 & 7509 & DL-H & 0 & 0.754 & 6.93 & Pass \\
18 & 7510 & DL-H & 45 & 0.873 & 6.74 & Fail \\
19 & 7629 & DL-H & 0 & 0.833 & 6.91 & Fail \\
\hline
\end{tabular}

Table 3: Impact test results.

In order to evaluate the effect of interchanging aluminum honeycomb for open-cell aluminum foam, a direct comparison can be made between impact damages induced on both configurations at nominally-identical impact conditions. In Fig. 6 damages induced in the DL-H and DL-F targets by the impact of $0.833 \mathrm{~cm}$ diameter projectiles at $6.83 \pm 0.09 \mathrm{~km} / \mathrm{s}$ with normal incidence are compared. Damage in the two mesh layers, and the entry hole on the $1^{\text {st }}$ sandwich panel are similar for both configurations. The diameter of rear facesheet material peeled back from the $1^{\text {st }}$ sandwich panel exit hole is also similar; however the extension of core damage is noticeably less in the foam. The through hole in the $2^{\text {nd }}$ panels is shown to be significantly larger for the DL-H configuration than the DL-F shield $(88 \times 90 \mathrm{~mm}$ vs. $70 \times 62 \mathrm{~mm})$, indicating that the debris cloud is more finely concentrated by the foam sandwich panel bumper than the honeycomb sandwich panel. The diameter of the through hole in the $2^{\text {nd }}$ panels is similar to that of the core damage in the first sandwich panel for both configurations $(\sim 91$ vs. $84 \mathrm{~mm}$ for DL-H; $\sim 58$ vs. $\sim 66 \mathrm{~mm}$ for DL-F). This suggests that the facesheets on the $2^{\text {nd }}$ panel of the DL-H configuration have little effect on the expansion of the debris cloud (i.e. they have minimal re-focusing effect).

The rear wall of the DL-H configuration is perforated, showing a large through crack $(80 \mathrm{~mm}$ in length, $5 \mathrm{~mm}$ wide) and multiple individual craters. Given the appearance of the through crack, it is expected that failure of the rear wall occurred through penetration of individual solid fragments which acted as crack initiation sites that were propagated during the impulsive load of the fragment cloud. The rear wall of the DL-F configuration is significantly deformed, yet there is no perforation or detachment of spalled material from the rear surface. The majority of deposits on the rear wall are from molten aluminum, visible as the bright silver coating in the target photograph. The rear wall shows some cratering from impact of individual solid fragments, which form small dimples on the rear side of the panel. Under these impact conditions, the performance of the DL-F shield is clearly superior to that of the baseline DL-H shield.

\section{Evaluation of shield performance}

The effect of secondary projectile and bumper fragment impacts upon individual foam cell ligaments is expected to lead to increased fragmentation, melting and vaporization at lower velocities than for conventional shielding configurations (e.g. Whipple shield, honeycomb sandwich panel). This mechanism is utilized in the multi-shock shield, which was shown in [9][10] to provide damage features at $6.3 \mathrm{~km} / \mathrm{s}$ representative of those seen at $10 \mathrm{~km} / \mathrm{s}$ on single bumper shields. An approximation of effective impact velocities can be made from projectile entropy (or internal energy). In [11] Swift calculates required impact velocities for melt and vaporization conditions based on the concept of entropy trapping - in which the entropy injected into projectile and target materials can be calculated from the Hugoniot and release isentrope. The increase in entropy acts to raise the material internal energy (or temperature), eventually reaching and exceeding the material fusion energy (melting) and vaporization energy.

The rear walls of the DL-H target in Fig. 6 shows a degree of molten aluminum deposits, although the predominant damage feature is cratering about the central damage zone. Alternatively, the DL-F target shows significant molten aluminum over a large central area with only a small number of finite craters. Clearly, therefore, secondary impacts on the foam ligaments are effective in raising fragment entropy. 

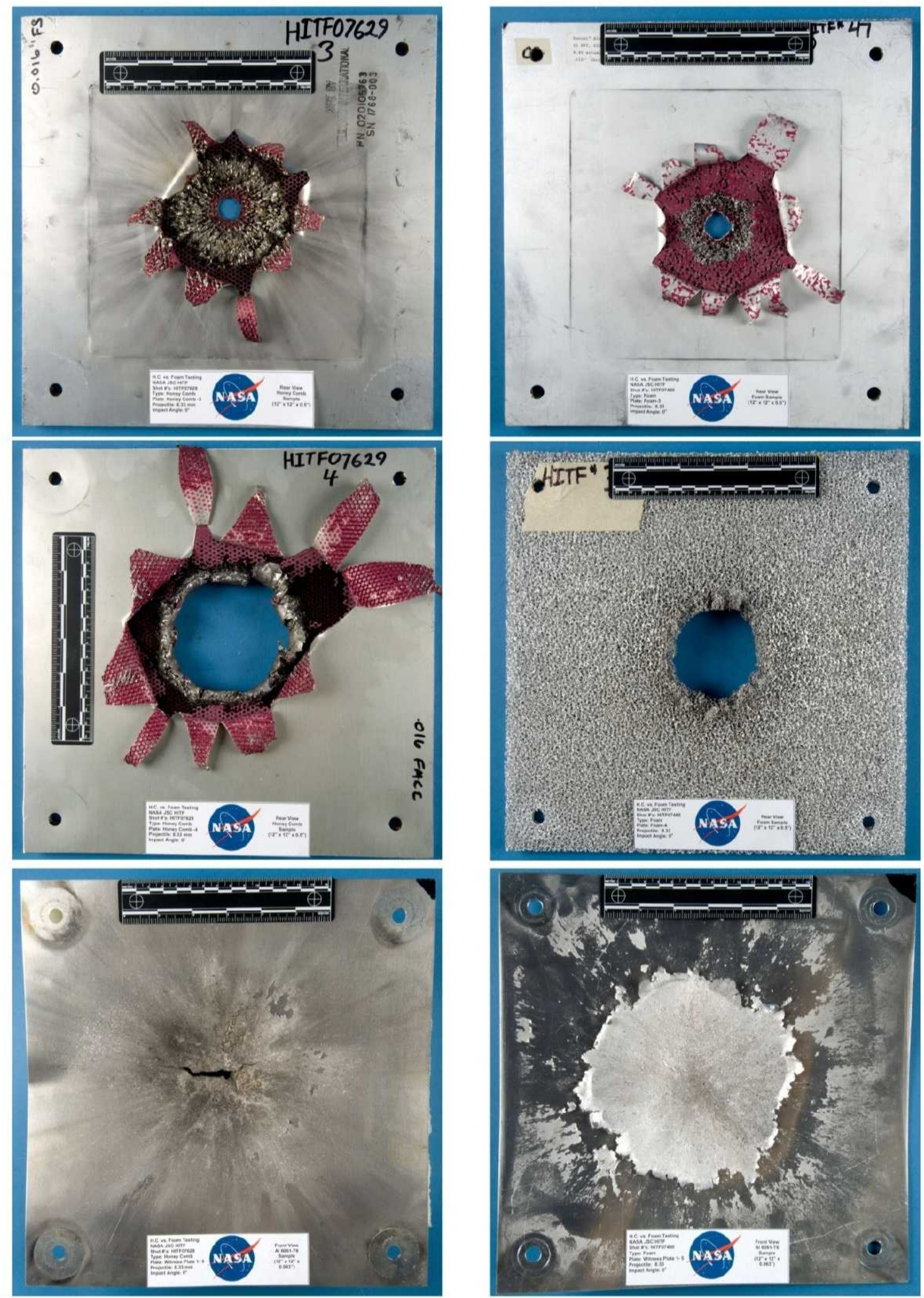

Fig. 6: Comparison of impact damages in the DL-H (left) and DL-F (right) targets impacted by $0.833 \mathrm{~cm}$ diameter Al2017-T4 spheres at $\sim 6.9 \mathrm{~km} / \mathrm{s}$ with normal incidence $\left(0^{\circ}\right)$. From top to bottom: $1^{\text {st }}$ sandwich panel (rear view), $2^{\text {nd }}$ panel (rear view), rear wall (front view). 


\section{BALLISTIC LIMIT EQUATIONS}

To evaluate the effect of the shielding modifications over the complete range of expected in-orbit impact conditions, ballistic limit curves can be used. Calculated using empirical ballistic limit equations (BLEs), these curves demarcate between impact conditions leading to pass or fail, and are used in modern risk assessment codes such as NASA's BUMPER-II to determine mission risk to micrometeoroid and orbital debris (MMOD).

The DL-H configuration is representative of the enhanced zone 11 shield onboard the FGB module of the ISS (Zarya) [12]. For FGB shielding, a generic ballistic limit equation was defined based on the NNO Whipple shield equation [6]. In order to adjust the equation to suit the double-layer honeycomb configuration, the bumper thickness was estimated using the areal density of the $1^{\text {st }}$ honeycomb sandwich panel, and half the areal density of the $2^{\text {nd }}$ sandwich panel. The remaining $50 \%$ of the $2^{\text {nd }}$ sandwich panel areal density was added to the thickness of the shield rear wall, and the equation constants were empirically adjusted from test data. The enhanced zone 11 FGB ballistic limit equation is defined (from [12]) as:

High velocity: when $\mathrm{V} \geq 7 / \cos \theta$,

$$
d_{c}=C_{H}(V \cos \theta)^{-2 / 3} \rho_{p}^{-1 / 3}
$$

where $\quad$ V-Projectile velocity $(\mathrm{km} / \mathrm{s})$

$\mathrm{V}_{\mathrm{L}}$ - Low velocity regime upper limit $(\mathrm{km} / \mathrm{s})$

$\mathrm{d}_{\mathrm{c}}-$ Critical projectile diameter $(\mathrm{cm})$

$\mathrm{C}_{\mathrm{H}}-$ High velocity fit coefficient $(-)=4.651$

$\theta$ - Impact angle (deg)

$\rho_{p}$ - Projectile density $\left(\mathrm{g} / \mathrm{cm}^{3}\right)$

Intermediate: when $3 / \cos \theta>V>7 / \cos \theta$,

$$
\begin{aligned}
d_{c}= & C_{h i} \rho_{p}^{-1 / 3}\left(V \cos \theta-V_{L}\right)+\ldots \\
& C_{l i} \rho_{p}^{-9 / 19}(\cos \theta)^{-18 / 19}\left(V_{H}-V \cos \theta\right)
\end{aligned}
$$

where $\quad \mathrm{V}_{\mathrm{H}}-$ High velocity regime lower limit $(\mathrm{km} / \mathrm{s})$

$\mathrm{C}_{\mathrm{hi}}-$ Inter-high velocity fit coefficient $(-)=0.318$

$\mathrm{C}_{\mathrm{li}}$ - Inter-low velocity fit coefficient $(-)=0.203$

Low velocity: when $\mathrm{V} \leq 3 / \cos \theta$,

$$
d_{c}=C_{L}(\cos \theta)^{-30 / 19} V^{-12 / 19} \rho_{p}^{-9 / 19}
$$

where $\quad C_{L}-$ Low velocity fit coefficient $(-)=1.629$

The diameter of the steel wire used in the enhanced zone 11 shield was $0.280 \mathrm{~mm}$, less than that of the DL-H configuration tested in this study $(0.4064 \mathrm{~mm})$. As such, the ballistic limit equation constants must be adjusted in order to fit the test data reported in Table 3. The low and high velocity coefficients, $\mathrm{C}_{\mathrm{L}}$ and $\mathrm{C}_{\mathrm{H}}$ respectively, are calculated based on the areal densities of the individual shield components:

$$
\begin{gathered}
C_{L}=3.11\left(t_{w}+\frac{\left(2 A D_{\text {mesh }}+A D_{S P 1}+A D_{S P 2}\right)}{2.8}\right) \\
C_{H}=3.52+3.0 A D_{\text {mesh }}
\end{gathered}
$$

The intermediate fit coefficients are calculated as 0.209 and 0.290 for $\mathrm{C}_{\mathrm{li}}$ and $\mathrm{C}_{\mathrm{hi}}$ respectively.

For the DL-F configuration, the areal densities of the specific shield components are also included in the equation fit coefficients. For honeycomb sandwich panels, the mass of the core is generally ignored in determining effective shield thicknesses (i.e. treated as non-ballistic mass). For foam core sandwich panels, however, the foam is an active shielding component. The ballistic limit equation for the DL-F configuration is defined as:

High velocity: when $\mathrm{V} \geq \mathrm{V}_{\mathrm{H}} / \cos \theta$,

$$
d_{c}=C_{H}(V \cos \theta)^{-\beta} \rho_{p}^{-1 / 3}
$$

where $\quad \beta$ - High velocity angle dependence constant $(-)=0.55$

$$
C_{H}=3.0+2.4 \times A D_{\text {mesh }}
$$

Inter. velocity: when $\mathrm{V}_{\mathrm{L}} / \cos \theta>\mathrm{V}>\mathrm{V}_{\mathrm{H}} / \cos \theta$,

$$
d_{c}=d_{c}\left(V_{L}\right)+\frac{d_{c}\left(V_{H}\right)-d_{c}\left(V_{L}\right)}{V_{H}-V_{L}} \cdot\left(V-V_{L}\right)
$$

Low velocity: when $\mathrm{V} \leq \mathrm{V}_{\mathrm{L}} / \cos \theta$,

$$
d_{c}=C_{L}(\cos \theta)^{-\alpha} V^{-12 / 19} \rho_{p}^{-9 / 19}
$$

where

$$
\begin{aligned}
& \alpha-\mathrm{LV} \text { angle dependence coefficient }(-)=1.75 \\
& C_{L}=3\left(t_{w}+\left(2 A D_{\text {mesh }}+A D_{S P 1}+A D_{S P 2}\right) / 2.8\right)
\end{aligned}
$$

In Fig. 7 the ballistic limit curve of the modified DLF shield is plotted against the baseline DL-H configuration. For normal impact, the modifications result in a small predicted improvement over the range of applicable impact velocities. At $3 \mathrm{~km} / \mathrm{s}$ the DL-F target provides a $15 \%$ improvement in critical projectile diameter, while at $7 \mathrm{~km} / \mathrm{s}$ a $3 \%$ increase is predicted. The larger low velocity sizing constant $\left(\mathrm{C}_{\mathrm{L}}\right)$ leads to increasing performance gain with increasing impact obliquity, although there is a lack of test data to support or disprove this extrapolation. 

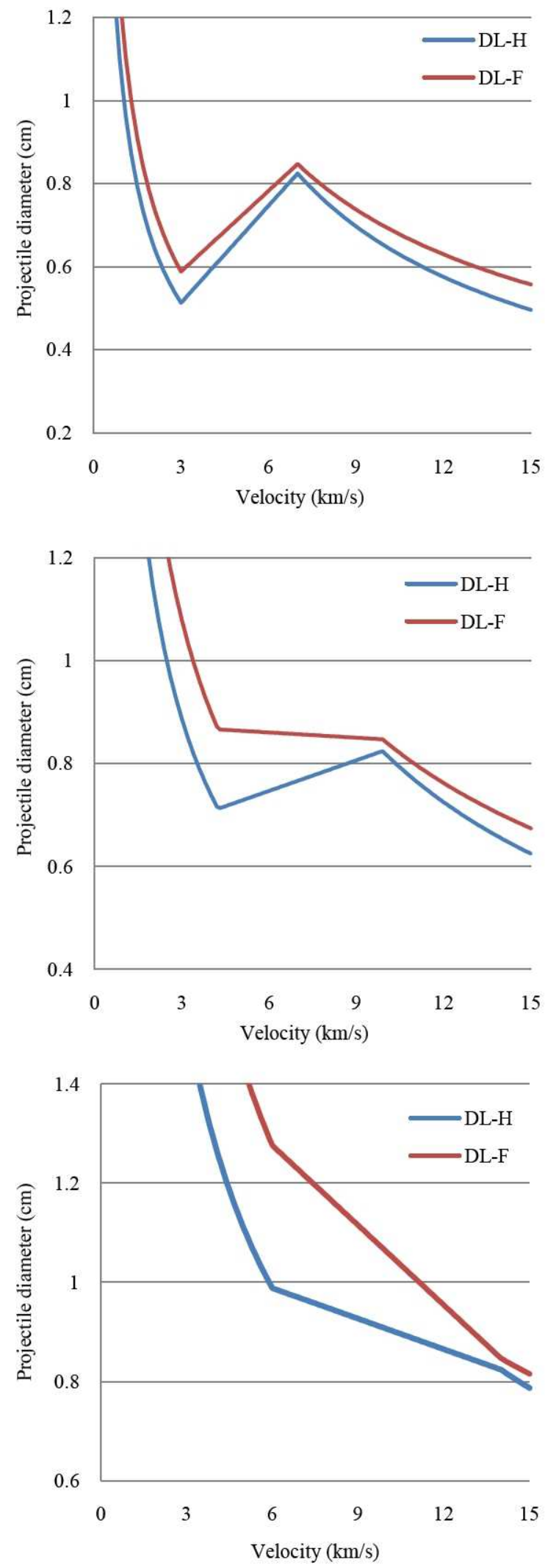

Fig. 7: Ballistic limit curves of the DL-H and DL-F shields. From top to bottom: $0^{\circ}, 45^{\circ}, 60^{\circ}$.

\section{DISCUSSION}

Sandwich panels with open-cell metallic foam cores provide comparable mechanical and thermal performance to those with metallic honeycomb cores for a minimal weight penalty. The homogenous foam structure avoids the MMOD shielding-detrimental channeling cells of honeycomb panels, making them a promising alternative for spacecraft primary structures which are also required to provide MMOD protection.

Destefanis et al. [13] reported on tests against a dual wall configuration with a bumper of open cell aluminum foam. In the tests a good deal of melting was observed at velocities as low as $2 \mathrm{~km} / \mathrm{s}$, with complete melting reported at velocities as low as 4 $\mathrm{km} / \mathrm{s}$. Similar enhanced fragmentation was reported in [14] for mm-sized projectiles at normal impact. In this study, clear evidence of melted deposits was observed on the target rear wall for test \#4 (HITF08595), performed at $3.29 \mathrm{~km} / \mathrm{s}$. For low velocity impacts at oblique impact (e.g. test \#6 (HITF08596)) there was also clearly observable deposits of melted aluminum upon the shield rear wall. Although the onset and degree of projectile and bumper melt is clearly increased by the open-cell foam bumpers, in all impact tests performed there is evidence of solid fragment impacts upon the target rear walls. For oblique impacts, these solid fragment craters are generally in-line with the projectile velocity vector, indicating that they are most likely projectile remnants.

In [14], the velocity regime transition limits of a ballistic limit equation for the foam bumper shielding configuration were set at 2.7 and $6.5 \mathrm{~km} / \mathrm{s}$ respectively, in recognition of the increased fragmentation and melting provided by the structure (compared to a traditional Whipple shield). However, due to the evidence of individual solid fragment impacts upon the shield rear wall for impact velocities up to $6.76 \mathrm{~km} / \mathrm{s}$ in this study, and in the absence of additional test data providing clear experimental justification, the transition velocities defined in [6] for aluminum Whipple shields and in [12] for the DL-H configuration are maintained in the ballistic limit equation derived for the DL-F shield.

Enhanced fragmentation and melting induced by the foam microstructure was found in [13] to be ineffective against projectiles in the $\mathrm{cm}$-sized range at normal incidence, and $\mathrm{mm}$-sized projectiles at oblique angles. The authors concluded that secondary impacts were no longer able to induce fragmentation and melting of the entire projectile at these impact 
conditions. In this study, however, there was no noticeable decrease in performance at obliquity, even for projectiles considerably larger than $1 \mathrm{~cm}$ in diameter (e.g. test \#11 (HITF09064)). The double layer of mesh on top of the $1^{\text {st }}$ sandwich panel of the DL-F configuration is expected to break up the projectile prior to impact on the sandwich panel facesheet. Therefore, smaller projectile fragments are propagated to impact within the sandwich panel foam core and the size-limitations of secondary fragmentation and melting discussed by Destefanis et al. are not valid.

\section{CONCLUSIONS AND SUMMARY}

In this paper, the effect on shielding performance achieved by replacing metallic honeycomb cores for metallic open-cell foam cores in a double sandwich panel MMOD shielding configuration representative of those used onboard the ISS was assessed. A baseline double-layer honeycomb (DL-H), and modified double-layer foam (DL-F) configuration were subject to impact by projectiles at hypervelocity, from which ballistic limit equations were derived. These equations were based on the NNO Whipple shield [6] and general FGB [12] equations, and included fit coefficients based on areal densities of individual shielding components. At normal incidence the foam-modified shield was found to provide a $15 \%$ improvement in critical projectile diameter at low velocity (i.e. $3 \mathrm{~km} / \mathrm{s}$ ) and a $3 \%$ increase at high velocity $(7 \mathrm{~km} / \mathrm{s})$. With increasing impact obliquity the foam shield performance enhancement increases at the lowshatter regime transition velocity, up to a $29 \%$ improvement in critical diameter at $60^{\circ}$. It should be noted that the double-layer honeycomb equation constants are defined for consistency with the enhanced zone 11 shield described in [12], for which there is no low velocity test data.

The presence of honeycomb cells is considered to be detrimental to the shielding performance of a dualwall configuration due to the cell walls acting to restrict the expansion of projectile and bumper (or front facesheet) fragments - referred to as channeling. However, the thickness of the honeycomb sandwich panels in the double-layer configuration are less than twice the diameter of even the smallest projectile used in the testing. Thus, dispersion of the projectile and bumper fragments is expected to be uninterrupted prior to impact upon the sandwich panel rear facesheet. As such, the performance enhancement gained by replacing the honeycomb core with open-cell foams is not expected to result as a simple absence of through-thickness channeling cells. Rather, secondary impacts of projectile and bumper fragments upon individual foam cell ligaments induced repeated shocks, increasing fragment entropy and subsequently reducing failure strengths. Evidence of increased projectile fragmentation and melting was shown for the double-layer foam configuration (compared to the double-layer honeycomb configuration). Previous investigations on metallic open-cell foam bumpers have noted a decrease in performance for oblique impact, and normal impact of large cm-sized projectile due to an inability of the repeated shocking procedure to fragment the entire projectile at these conditions. However, the presence of the double mesh outer layers breaks up the projectile prior to impact upon the $1^{\text {st }}$ sandwich panel front facesheet, ensuring the propagation of smaller, more manageable impactors within the foam core.

\section{REFERENCES}

[1] D.W. Jex, A.M. Miller, C.A. MacKay, "The Characteristics of Penetration for a Double-Sheet Structure with Honeycomb", NASA Marshall Space Flight Center, Huntsville, NASA TM X53974, 1970.

[2] J-M. Sibeaud, C. Thamie, C. Puillet, "Hypervelocity Impact on Honeycomb Target Structures: Experiments and Modeling", International Journal of Impact Engineering; 35: 1799-1807, 2008.

[3] E.A. Taylor, M.K. Herbert, B.A. Vaughan, J.A. McDonnell, "Hypervelocity Impact on Carbon Fibre Reinforced Plastic / Aluminum Honeycomb: Comparison with Whipple Bumper Shields", International Journal of Impact Engineering; 23(1): 883-893, 1999.

[4] S. Ryan, F.K. Schaefer, R. Destefanis, M. Lambert, "A Ballistic Limit Equation for Hypervelocity Impacts on CFRP/Al HC Satellite Structures", Advances in Space Research; 41: 1152-1166, 2008.

[5] R. Sennett, B. Lathrop, "Effects of Hypervelocity Impact on Honeycomb Structure", Journal of Spacecraft; 5(12): 1496-1497, 1968.

[6] E.L. Christiansen, "Design and Performance Equations for Advanced Meteoroid and Debris Shields", International Journal of Impact Engineering; 14(1-4): 145-156, 1993.

[7] R. Destefanis, "Enhanced Space Debris Shields for Manned Spacecraft - Evaluation Report: Phase A and Phase B Tests", Alenia-Spazio, Turin, ESD-TN-Al-005, 2004. 
[8] J. Yasensky, E.L. Christiansen, T. Prior, "Hypervelocity Impact Evaluation of Metal Foam Core Sandwich Structures", GeoControl Systems, Houston, NASA TP-2008-214776, 2008.

[9] B.G. Cour-Palais, J.L. Crews, "A Multi-Shock Concept for Spacecraft Shielding", International Journal of Impact Engineering; 10: 135-146, 1990.

[10]M. Alme, E. Christiansen, B. Cour-Palais, "Hydrocode Simulations of the Multi-Shock Meteoroid and Debris Shield", Shock Compression of Condensed Matter 1991, pp. 975-978, 1991.

[11]H.F. Swift, "Hypervelocity Impact Mechanics", in: Impact Dynamics (Zukas, ed.), John Wiley \& Sons, New York, 1982.

[12] G.A. Sanchez, E.L. Christiansen, "FGB Energy Block Meteoroid and Orbital (M/OD) Debris Shield Test Report", NASA Johnson Space Center, Houston, JSC Document 27460, 1996.

[13]R. Destefanis, F. Schaefer, M. Lmabert, M. Faraud, E. Schneider, "Enhanced Space Debris Shields for Manned Spacecraft", International Journal of Impact Engineering; 29: 215-226, 2003.

[14]R. Destefanis, F. Schaefer, M. Lambert, M. Faraud, "Selecting Enhanced Space Debris Shields for Manned Spacecraft", International Journal of Impact Engineering; 33: 219-230, 2006. 